\title{
PHOSPHORUS IN SINTERED STEELS: EFFECT OF PHOSPHORUS CONTENT AND P CARRIER IN SINTERED STEEL Fe-C-P
}

\author{
B. Üregen, C. Gierl-Mayer, H. Danninger
}

\begin{abstract}
Phosphorus as an alloy element is quite common in powder metallurgy, the contents industrially used being markedly higher than those present in wrought steels. In this study, the influence of phosphorus addition through different $P$ carriers was investigated. PM steels of the type Fe$0.7 \% C-x \% P(x=0.0 \ldots 0.8 \%)$ were manufactured by pressing and sintering in H2. It showed that Fe3P is the best phosphorus carrier, resulting in fine and regular microstructure and in high impact energy data at $0.3 \ldots 0.45 \% P$ while red $P$ and also Fe2P showed a tendency to agglomeration, with resulting secondary porosity. At high $P$ levels the mechanical properties tend to drop, for the tensile strength at $P>$ $0.60 \% P$ while for the impact energy the threshold is $0.45 \% P$. The dimensional behaviour of $\mathrm{Fe}-\mathrm{C}-\mathrm{P}$ can be related to $\mathrm{PM}$ aluminium alloys, expansion by transient liquid phase being followed by shrinkage by persistent liquid phase, at least at higher temperatures. In contrast to the dimensional behaviour, degassing and reduction is hardly affected by the phosphorus content.
\end{abstract}

Keywords: Sintered steels, phosphorus, $P$ carriers, dimensional behaviour, degassing

\section{INTRODUCTION}

While phosphorus is a highly undesirable component in wrought steels the content of which is kept at as low levels as possible, it is frequently added to PM steels in considerable levels, typically up to 0.6 mass $\%$, its beneficial effects having been known for a long time [1-5]. In ingot metallurgy, the pronounced tendency of $\mathrm{P}$ to segregation, supported by the very low-melting eutectic Fe-P, causes severe problems, and P levels in wrought steels are typically $<0.01 \%$, except for some transformer core steel sheet grades which may contain up to $0.1 \%$, which is however still much less than the phosphorus contents common in P containing powder metallurgy steels. For PM steels the beneficial activating - effect of $\mathrm{P}$ on the sintering of ferrous materials is used which e.g. in PM iron results in strength considerably higher than of plain Fe combined with at least comparable ductility (e.g. [6-8]). The effects of P addition to PM steels have therefore been studied extensively by numerous research groups, see e.g. [9-13].

This positive effect of $\mathrm{P}$ is in part attributed to $\mathrm{P}$ being a ferrite stabilizing element. In $\alpha$ iron, the diffusional processes are much faster than in $\gamma$-iron which is the modification normally stable at sintering temperature [14], and sintering thus also proceeds at a much higher rate, similar to the effect of Mo addition [15]. Sintering in the two-phase field has been described to be particularly beneficial for the mechanical properties [16]. Furthermore, 
$\mathrm{P}$ forms a transient liquid phase with Fe due to the low temperature of the Fe-P eutectic of only about $1050^{\circ} \mathrm{C}[17,18]$, at least at higher heating rates [19], which also accelerates sintering [20], the effect of $P$ thus also depending on the heating rate applied [21, 22]. In industrial practice, addition of $\mathrm{P}$ as an activator to $\mathrm{PM}$ steels is popular because it enables sintering in standard mesh belt furnaces, at temperatures of about $1120^{\circ} \mathrm{C}$, resulting in properties that in the case of P-free steels, would require temperatures exceeding $1200^{\circ} \mathrm{C}$ and thus more expensive walking beam furnaces. Phosphorus addition has been done through different carriers, ferrophosphorus Fe3P being the most commonly used variant, although also elemental $\mathrm{P}$ has been tested [23, 24].

However, there have been also numerous reports about embrittlement phenomena in P containing sintered steels. These effects are attributed e.g. to the transient liquid phase which leaves oxide traces at the grain boundaries [25] or to impurities contained by the ferrophosphorus used [26]. Small amounts of carbon reportedly are beneficial towards the dimensional and mechanical behaviour [11,27] while other authors claim that carbon tends to promote embrittlement, in particular when combined with VIa alloy elements [28].

In the present study, the effect of introducing $\mathrm{P}$ through different carriers has been investigated, and for the best variant the dimensional and degassing behaviour during sintering have been studied.

\section{EXPERIMENTAL TECHNIQUE}

To study the effect of the way phosphorus was added to the sintered steel, plain $\mathrm{Fe}-0.7 \% \mathrm{C}-\mathrm{x} \% \mathrm{P}$ powder mixes - alloying elements being excluded to avoid introducing additional effects - were prepared. Varying amounts of $\mathrm{P}$ were added through different $\mathrm{P}$ carriers. The carbon content was chosen relatively high to reveal embrittling effects more clearly [12]. The specimens were prepared from iron powder ASC 100.29 (Höganäs AB), and natural graphite Kropfmühl UF4 (purified grade, ash content $<1 \mathrm{wt} \%$ ). For the standard test specimens, $0.5 \%$ HWC was added as pressing lubricant while the dilatometric specimens were prepared without pressing aid, die wall lubrication being afforded instead. Various phosphorus carriers were tested, including plain red $\mathrm{P}$ powder (Merck), ferrophosphorus Fe3P and Fe2P $(<30 \mu \mathrm{m}$, both supplied by MIBA Sinter Austria GmbH, images are shown in Fig.1) and Höganäs premix PASC100.45. For PASC100.45, which contains $0.45 \% \mathrm{P}$ as delivered. In this case, the lower P levels were set by diluting the PASC with standard ASC100.29 (which is the base powder for PASC anyhow), and levels $>0.45 \%$ were attained by admixing fine Fe3P powder.

Mixtures of the desired compositions were prepared in a tumbling mixer, mixing being done for $1 \mathrm{hr}$. The mixes were then compacted at $700 \mathrm{MPa}$ to non-standard tensile test bars with cavity cross section of $456 \mathrm{~mm} 2$ (see [29, 30]) and sintered in a pushtype furnace (Degussa "Baby") in flowing hydrogen. After dewaxing in the entrance zone of the furnace, the boat with the specimens was pushed into the high temperature zone of the furnace, and after the defined sintering time it was pushed into the water-cooled exit zone. To avoid decarburization, getter boxes with $\mathrm{Al}_{2} \mathrm{O}_{3}-5 \% \mathrm{C}$ getter were used. Sintering was done isothermally at $1120^{\circ} \mathrm{C}$ for $1 \mathrm{hr}$, the effective temperature being controlled pyrometrically. The heating and cooling rates during this sintering procedure were in the range of 60-80 K. $\mathrm{min}^{-1}$ (linearized). 


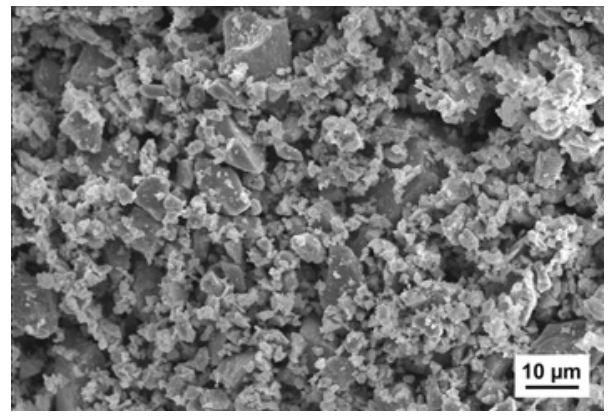

a) Fe2P. overview

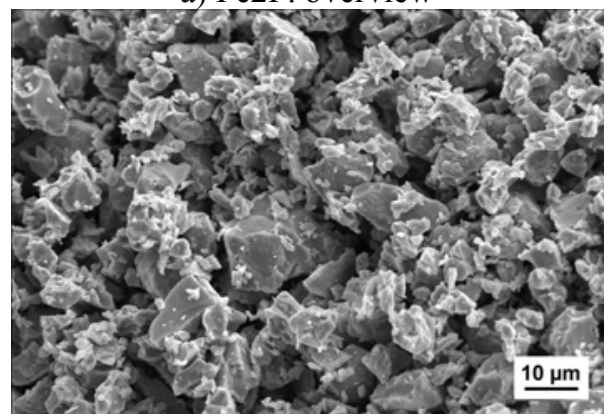

c) Fe3P. overview

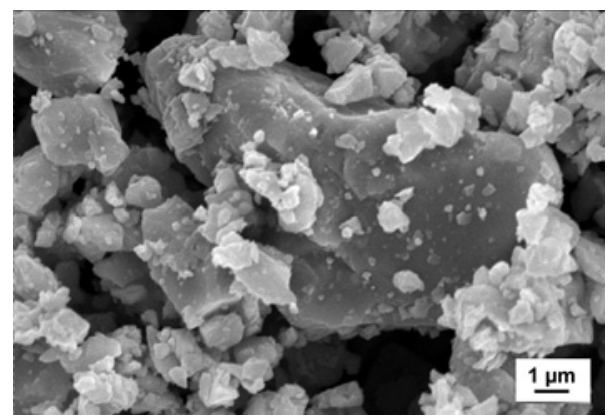

b) Fe2P. detail

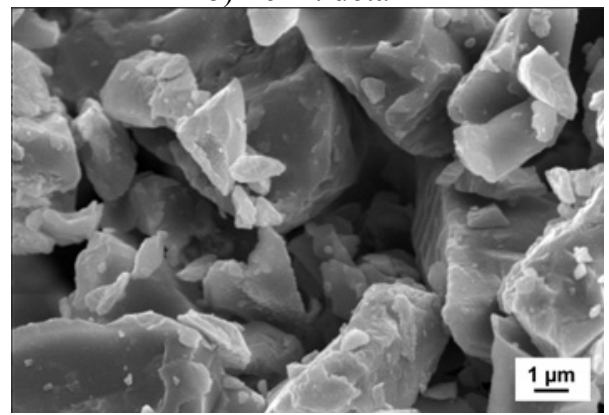

d) Fe3P. detail

Fig.1.SEM images of ferrophosphorus powder grades used.

The sintered samples were then tested following standard techniques, i.e. the green density was measured from the dimensions, and the sintered density was determined by water displacement (Archimedes method) after impregnation with a commercial waterstop spray. Furthermore, dimensional change during sintering and hardness HV30 were measured. Tensile tests were done on a universal testing machine Zwick 1474, and Charpy impact testing was performed on a Wolpert tester with $\mathrm{Wmax}=50 \mathrm{~J}$. Since the specimen shape was non-standard, the data obtained should not be taken as absolute values but relative to one another.

Sections were prepared by cutting pieces from the heads of the sintered bars, resin mounting, grinding with SiC paper, diamond polishing with $15 / 7 / 3 \mu \mathrm{m}$ diamond paste and then finish polishing with fine $\mathrm{Al}_{2} \mathrm{O}_{3}$. Etching was done with Nital $\left(\mathrm{MeOH}-3 \% \mathrm{HNO}_{3}\right)$.

For studying the dimensional and degassing behaviour, impact test bars (ISO 5754) of $55 \times 10 \times$ approx. $8 \mathrm{~mm}$ were compacted at $600 \mathrm{MPa}$ with die wall lubrication, Multical sizing oil being used as lubricant. Sintering runs were performed in a pushrod dilatometer Netzsch 402 with alumina measuring system, and a mass spectrometer Netzsch Aeolos was connected to the dilatometer via a capillary coupling. The runs were performed at constant heating and cooling rates of $10 \mathrm{~K} \cdot \mathrm{min}^{-1}$, also here in reducing atmosphere of flowing hydrogen ( 99.999 purity). The dimensional change was recorded perpendicular to the pressing direction, i.e. between the die surfaces.

\section{Influence of the $P$ carrier on the properties of Fe-C-P}

The dimensional and mechanical properties are listed in Table 1 and in part graphically shown as a function of the $\mathrm{P}$ content in Fig.2. Minimum 4 paralle specimens were tested, and the scatter was fairly low except for the explicitly brittle specimens. 
Tab.1. Properties of Fe-0.7\%C-x\%P prepared using different $\mathrm{P}$ carriers. Compacted at 700 $\mathrm{MPa}$, sintered $1 \mathrm{~h} 1120^{\circ} \mathrm{C}$ in $\mathrm{H} 2$.

\begin{tabular}{|c|c|c|c|c|c|c|c|}
\hline $\begin{array}{c}\mathrm{P} \\
\text { content }\end{array}$ & $\begin{array}{c}\text { Green } \\
\text { Density }\end{array}$ & $\begin{array}{l}\text { Sintered } \\
\text { Density }\end{array}$ & $\begin{array}{l}\text { Dim. } \\
\text { change }\end{array}$ & UTS & $\begin{array}{l}\text { Elong- } \\
\text { ation }\end{array}$ & $\begin{array}{l}\text { Impact } \\
\text { energy }\end{array}$ & Hardness \\
\hline Mass $\%$ & g. $\mathrm{cm}^{-3}$ & g. $\mathrm{cm}^{-3}$ & $\%$ linear & $\mathrm{MPa}$ & $\%$ & $\mathrm{~J} . \mathrm{cm}^{-2}$ & HV30 \\
\hline \multicolumn{8}{|c|}{ Elemental (red) P } \\
\hline 0.0 & 7.27 & 7.27 & -0.11 & 437 & 7.3 & 21.5 & 164 \\
\hline 0.15 & 7.24 & 7.21 & 0.0 & 423 & 4.0 & 12.8 & 171 \\
\hline 0.3 & 7.23 & 7.16 & 0.0 & 469 & 4.8 & 19.9 & 171 \\
\hline 0.45 & 7.12 & 7.14 & 0.0 & 512 & 4.0 & 18.1 & 186 \\
\hline 0.6 & 7.10 & 7.13 & 0.0 & 546 & 5.2 & 16.8 & 191 \\
\hline 0.8 & 7.04 & 7.05 & -0.04 & 573 & 3.8 & 10.5 & 191 \\
\hline \multicolumn{8}{|c|}{ PASC 100.45} \\
\hline 0.0 & 7.27 & 7.27 & -0.11 & 437 & 7.3 & 21.5 & 164 \\
\hline 0.15 & 7.25 & 7.19 & 0.04 & 523 & 6.6 & 26.3 & 184 \\
\hline 0.3 & 7.23 & 7.12 & 0.18 & 559 & 4.6 & 23.4 & 198 \\
\hline 0.45 & 7.2 & 7.03 & 0.43 & 601 & 4.7 & 24.1 & 206 \\
\hline 0.6 & 7.18 & 6.99 & 0.58 & 620 & 5.0 & 22.5 & 210 \\
\hline 0.8 & 7.16 & 6.97 & 0.61 & 334 & 1.1 & 1.9 & 214 \\
\hline \multicolumn{8}{|c|}{$\mathrm{Fe}_{2} \mathrm{P}$} \\
\hline 0.0 & 7.27 & 7.27 & -0.11 & 437 & 7.3 & 21.5 & 164 \\
\hline 0.15 & 7.23 & 7.2 & -0.07 & 490 & 7.3 & 27.2 & 171 \\
\hline 0.3 & 7.21 & 7.11 & 0.29 & 529 & 5.8 & 28.4 & 177 \\
\hline 0.45 & 7.19 & 7.01 & 0.54 & 581 & 6.7 & 29.2 & 187 \\
\hline 0.6 & 7.16 & 6.9 & 1.16 & 590 & 4.0 & 13.8 & 191 \\
\hline 0.8 & 7.1 & 6.8 & 1.38 & 422 & 0.5 & 2.6 & 194 \\
\hline \multicolumn{8}{|c|}{$\mathrm{Fe}_{3} \mathrm{P}$} \\
\hline 0.0 & 7.27 & 7.27 & -0.11 & 437 & 7.3 & 21.5 & 164 \\
\hline 0.15 & 7.24 & 7.15 & 0 & 448 & 6.5 & 24.0 & 177 \\
\hline 0.3 & 7.22 & 7.14 & 0.07 & 541 & 6.4 & 38.2 & 184 \\
\hline 0.45 & 7.19 & 7.06 & 0.4 & 552 & 6.2 & 37.9 & 184 \\
\hline 0.6 & 7.16 & 7.01 & 0.5 & 622 & 5.4 & 24.9 & 191 \\
\hline 0.8 & 7.12 & 6.93 & 0.76 & 571 & 2.1 & 6.3 & 191 \\
\hline
\end{tabular}

It stands out clearly that not only the green but also the sintered densities decrease with higher P content, indicating that the well-known activation of sintering by phosphorus is not visible in the dimensional behaviour, at least not at the sintering conditions chosen here. If the different $\mathrm{P}$ carriers are compared it is evident that red $\mathrm{P}$ results in virtually stable dimensions; it yields the lowest green but the highest sintered density values since all other $\mathrm{P}$ carriers cause expansion, most pronouncedly Fe2P. This can be attributed to formation of transient liquid phase at the fairly high heating rates applied in the pushtype furnace; the coarser $\mathrm{Fe} 2 \mathrm{P}$ is more prone to form liquid phase than the finer $\mathrm{Fe} 3 \mathrm{P}$ for which interdiffusion below the eutectic temperature plays a more pronounced role. The effect of alloy element carrier particle size on transient liquid phase formation has been described e.g. in $[31,32]$. Elemental red $\mathrm{P}$ sublimes (vapour pressure of 1 bar at $417^{\circ} \mathrm{C}$ [33]) at a 
temperature at which both the solubility and the diffusivity in Fe are still fairly low and therefore does not exhibit the typical swelling associated with transient liquid phase; its high vapour pressure enables transfer to Fe through the gas phase (similar to Mn, see [34]). In any case, red $\mathrm{P}$ showed a pronounced tendency to form agglomerates during admixing (as already shown e.g. by Jangg et al. [24]) and therefore is not too well suited as P carrier.

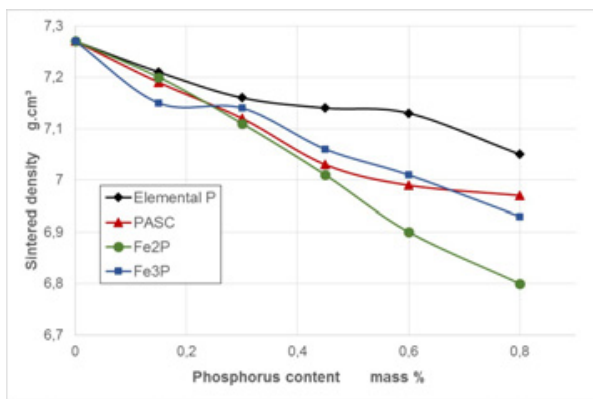

a) Sintered density

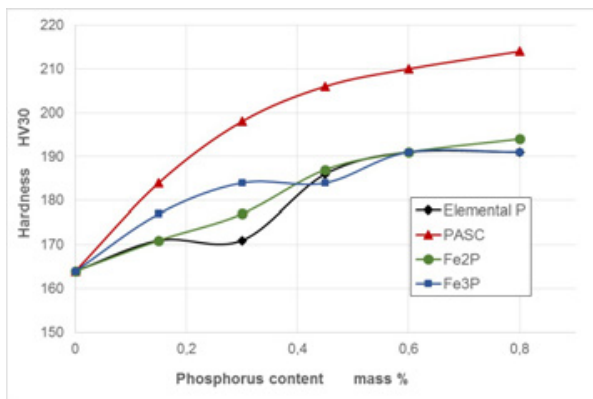

c) Hardness

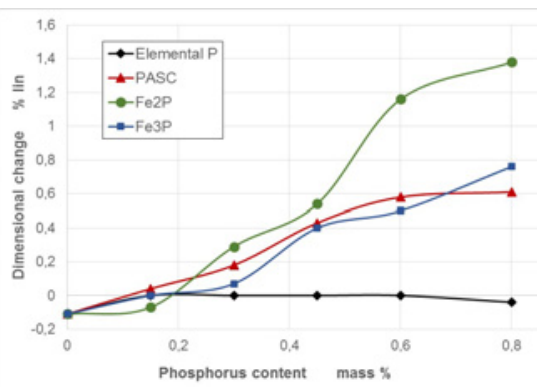

b) Dimensional change (relative to the green compact)

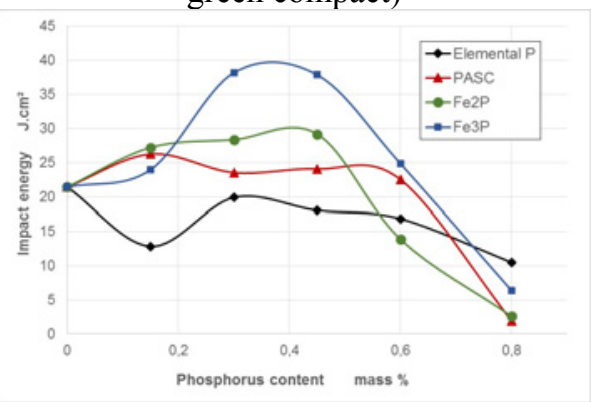

d) Impact energy (unnotched)

Fig.2. Properties of Fe- $0.7 \% \mathrm{C}-\mathrm{X} \% \mathrm{P}$ as a function of the $\mathrm{P}$ content. Different $\mathrm{P}$ carriers. compacted $700 \mathrm{MPa}$. sintered $1 \mathrm{~h} 1120^{\circ} \mathrm{C}$ in $\mathrm{H}_{2}$.

Regarding the mechanical properties, there is not too much difference between the various $\mathrm{P}$ carriers regarding $\mathrm{Rm}$ and $\mathrm{A}$; elemental $\mathrm{P}$ being usually slightly inferior to the other. The differences between the nominally equal variants ASC 100.29 + Fe3P and PASC 100.45 can be attributed to the different mixing techniques, lab vs. industrial mixing. It is however evident that for tensile strength the maximum is reached at $0.6 \% \mathrm{P}$ and then the values drop, while for the elongation there is more or less a constant level maximum (although with considerable scatter) up to $0.6 \% \mathrm{P}$ (for Fe2P: $0.45 \% \mathrm{P}$ ), and at higher $\mathrm{P}$ levels the elongation also drops. The hardness shows a more or less steady increase with higher $\mathrm{P}$ content, PASC yielding the highest values, while for the impact energy, $\mathrm{P}$ addition by $\mathrm{Fe} 3 \mathrm{P}$ definitely yields the best results, especially in the range $0.3-0.45 \% \mathrm{P}$, which agrees with previous findings described in the literature (e.g. [35]). At higher P levels, considerable embrittlement is observed with all $\mathrm{P}$ carriers, red $\mathrm{P}$ being most tolerant, though at a relatively low property level.

\section{Metallographic investigations}

In Fig.3, typical pore distribution patterns in Fe-C-P with varying $\mathrm{P}$ content are shown, $\mathrm{P}$ having been introduced as $\mathrm{Fe} 3 \mathrm{P}$. The progressive rounding of the pores with 
higher $\mathrm{P}$ content is clearly evident, but it can also be seen that the porosity does not visibly decrease as a consequence of $\mathrm{P}$ addition, which agrees with the density measurements. This can be attributed to the fact that the classical $\mathrm{P}$ activation through stabilization of ferrite, which usually also results in densification (see [15]) does not occur here, as a consequence of the fairly high carbon content, which, as an austenite stabilizer, outweighs the ferritestabilizing effect of phosphorus. Sintering thus occurs in the fully austenitic phase, as indicated also in the respective phase diagram [18].

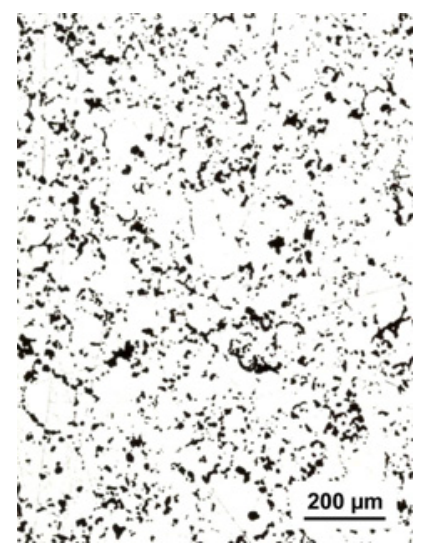

a) reference

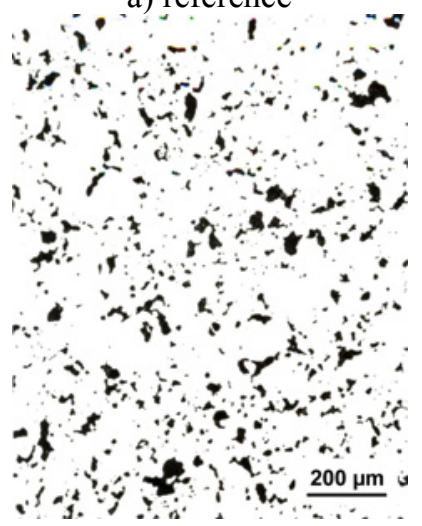

d) $0.45 \% \mathrm{P}$

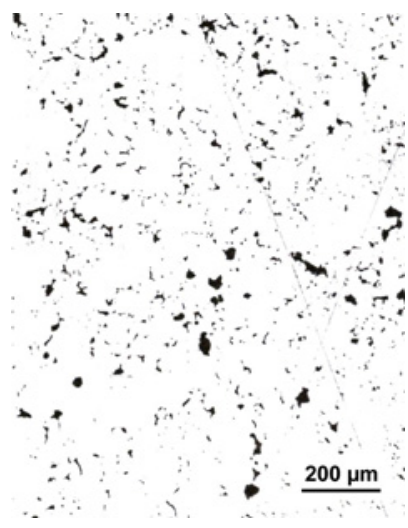

b) $0.15 \% \mathrm{P}$

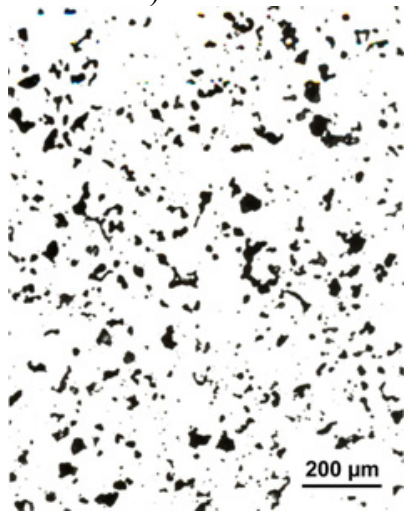

e) $0.60 \% \mathrm{P}$

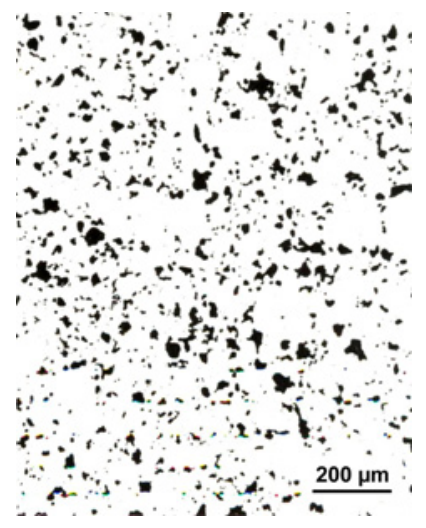

c) $0.30 \% \mathrm{P}$

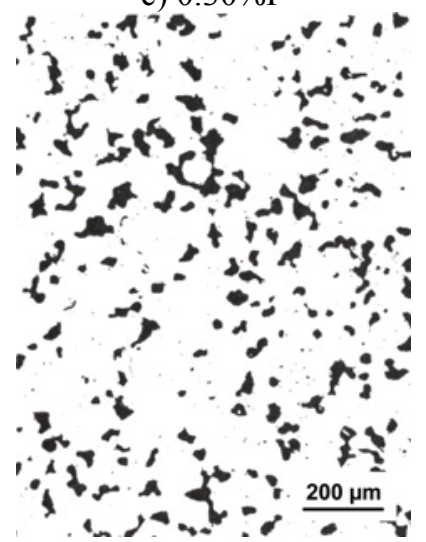

f) $0.80 \% \mathrm{P}$

Fig.3. Metallographic sections of Fe- $0.7 \% \mathrm{C}-\mathrm{x} \% \mathrm{P}$. phosphorus added as Fe3P. Compacted at $700 \mathrm{MPa}$. sintered $60 \mathrm{~min} 1120^{\circ} \mathrm{C}$ in $\mathrm{H}_{2}$.

On the other hand, activation has definitely occurred, as indicated by the pronounced pore rounding visible in particular at higher P levels. This can at least to some extent be attributed to formation of transient liquid phase (which is quite probable at the high heating rates applied here), but also to the considerable drop of the solidus temperature caused by $\mathrm{P}$ addition; i.e. also solid state sintering occurs at higher reduced temperatures Tsint/Tsolidus than in case of plain Fe-C.

When comparing the specimens prepared from different $\mathrm{P}$ carriers (Fig.4), the most pronounced feature is the emergence of relatively large, more or less rounded pores visible in those materials that have been prepared using red phosphorus, but also those from 
Fe2P. This indicates the presence of comparatively large $\mathrm{P}$ carrier particles, as shown in [19]. In the present case it also implies that both additives have been distributed fairly heterogeneously in the green compacts and have formed secondary pores during heating, as typical for systems with transient liquid phase if the melt-forming additives are sufficiently coarse to generate pores that are discernible from the primary pores. For red $\mathrm{P}$ the tendency to form agglomerates has been observed in previous studies (e.g. [24]). With Fe2P the effect is rather surprising since, as evident from the SEM images, this ferrophosphorus is even finer than Fe3P. It must be concluded that the tendency to form agglomerates is also more pronounced here. When comparing Fig. $4 \mathrm{c}$ and d, it stands out clearly that the bimodal pore structure - fine primary vs. coarse secondary pores - is more pronounced at $0.45 \% \mathrm{P}$; at the very high content of $0.80 \% \mathrm{P}$, the secondary pores are present, too, but since the primary pores have coarsened considerably, as a consequence of persistent liquid phase sintering, their size is close to that of the secondary pores, and the latter thus are less clearly visible.

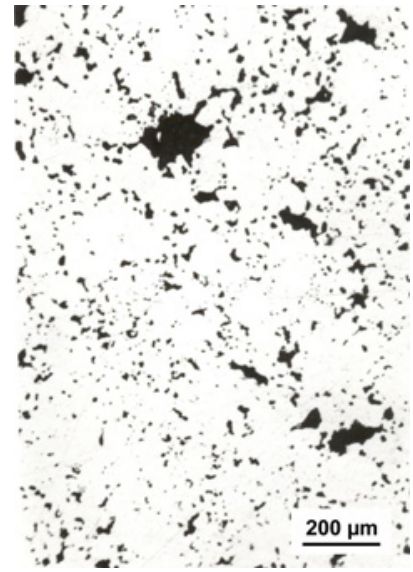

a) $0.45 \% \mathrm{P}$. as red $\mathrm{P}$

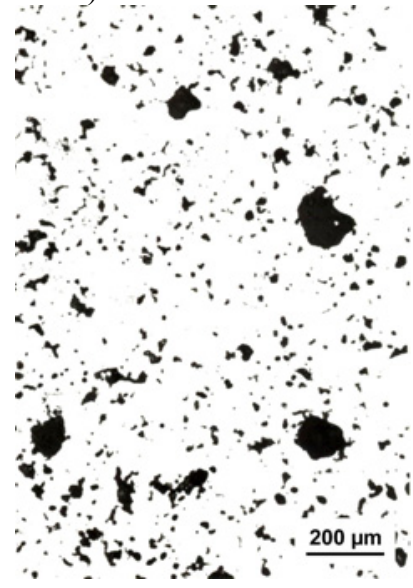

c) $0.45 \% \mathrm{P}$. as Fe $2 \mathrm{P}$

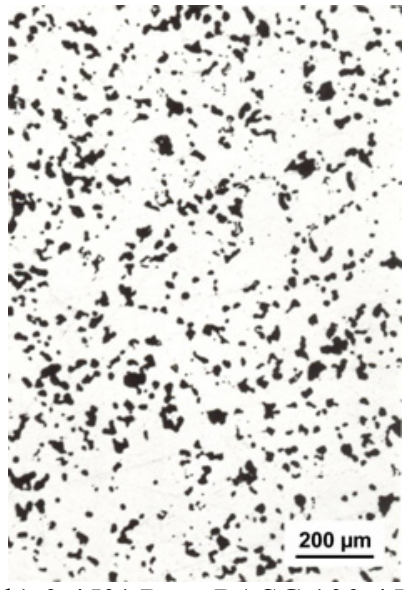

b) $0.45 \%$ P. as PASC 100.45

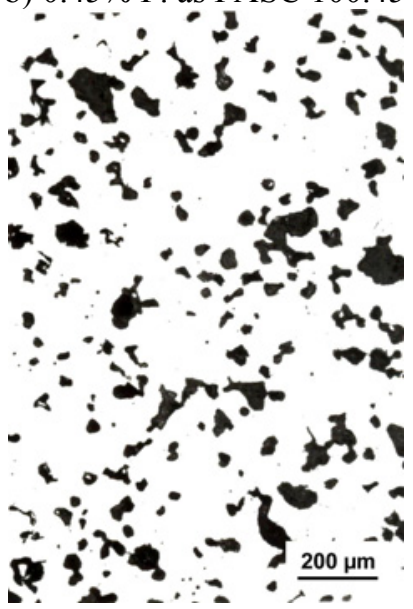

d) $0.80 \%$ P. as Fe $2 \mathrm{P}$

Fig.4. Metallographic sections of $\mathrm{Fe}-0.7 \% \mathrm{C}-\mathrm{x} \% \mathrm{P}$. phosphorus added through different carriers. Compacted at $700 \mathrm{MPa}$. sintered $60 \mathrm{~min} 1120^{\circ} \mathrm{C}$ in $\mathrm{H}_{2}$. 
In the case of $\mathrm{P}$ being introduced through PASC 100.45, as well as for Fe3P (see Fig.3d), the pore structure is quite regular, indicating that also the distribution of the $\mathrm{P}$ carrier particles in the green compact has been homogeneous. I.e. those ways to introduce phosphorus into the sintered steels seem to be preferable, as also indicated by the mechanical properties.

\section{Influence of $P$ content, added as Fe3P, on dimensional and degassing behaviour}

In order to investigate the effect of the phosphorus content on the dimensional behavior during sintering and also on degassing and reduction phenomena, dilatometric runs were performed in reducing $\left(\mathrm{H}_{2}\right)$ atmosphere. Fe3P was used as $\mathrm{P}$ carrier since the previous studies had clearly shown that it is the most suitable $\mathrm{P}$ source. As stated above, compacts $55 \times 10 \times$ ca. $8 \mathrm{~mm}$ were prepared from ASC 100.29, graphite UF4 and Fe3P by mixing and pressing at $600 \mathrm{MPa}$ with die wall lubrication. The dilatometric runs were performed at heating and cooling rates of $10 \mathrm{~K}$.min-1.

The isothermal sintering temperature was the same for all specimens, regardless of the $\mathrm{P}$ content; this was done to show the effect of $\mathrm{P}$ on the sintering behavior more clearly, although of course in industrial practice the sintering temperature is adjusted to the $\mathrm{P}$ content, i.e. lowered at higher $\mathrm{P}$ levels, also to make full use of the activating effect of $\mathrm{P}$ and lower the cost of sintering. For the studies done here, in contrast, the effect of $\mathrm{P}$ addition was expected to be more evident if comparison was done at the same isothermal temperature; also the soaking time was kept constant at $60 \mathrm{~min}$.

In Fig.5, the dilatograms of the specimens with varying $\mathrm{P}$ content are compared. As can be seen from the graphs, there is hardly any difference between the reference material Fe-C and the variant containing $0.15 \% \mathrm{P}$; after the $\alpha-\gamma$ transformation there is first a marked expansion followed by a virtually linear one right up to the sintering temperature. Also during isothermal sintering, shrinkage is virtually identical for both materials, indicating that the activating effect of $\mathrm{P}$ at this content is not really discernible, which agrees with the mechanical properties. With increasing $\mathrm{P}$ content the phase transformation is shifted to slightly lower temperatures, which is somewhat surprising considering the well known $\alpha$-stabilizing effect of P. However it should not be ignored that the main factor for the phase transformation is the dissolution of carbon in the matrix, which might be affected by admixing Fe3P powder, the latter acting as additional transport surface for the carbon. Also damage to the surfaces of the base powder particles by the hard Fe3P particles may be supposed to enhance carbon dissolution. In any case, $\mathrm{P}$ homogenization is surely much slower in this temperature range than that of $\mathrm{C}$ (according to [33], at $800^{\circ} \mathrm{C}$ the diffusion coefficient of $\mathrm{P}$ in austenite is $1.2 .10 \mathrm{E}-11 \mathrm{~cm}^{2} / \mathrm{s}$ compared to $1 . \overline{7} .10 \mathrm{E}-8 \mathrm{~cm}^{2} / \mathrm{s}$ for carbon, and even in ferrite it is only $1.7 .10 \mathrm{E}-11 \mathrm{~cm}^{2} / \mathrm{s}$ ), and therefore there should not be any effect of $\mathrm{P}$ on the transformation. From $0.3 \% \mathrm{P}$ there is an increasingly significant "jump" in the graphs, i.e. a pronounced expansion, starting at about $950{ }^{\circ} \mathrm{C}$ and extending to increasingly higher temperatures with higher $\mathrm{P}$ content. This can be taken as an indicator for formation of transient liquid phase since the steadite eutectic is formed at this temperature [18], as indicated in the graph. Formation of this transient eutectic liquid phase has already been described by Molinari et al. [11]. 


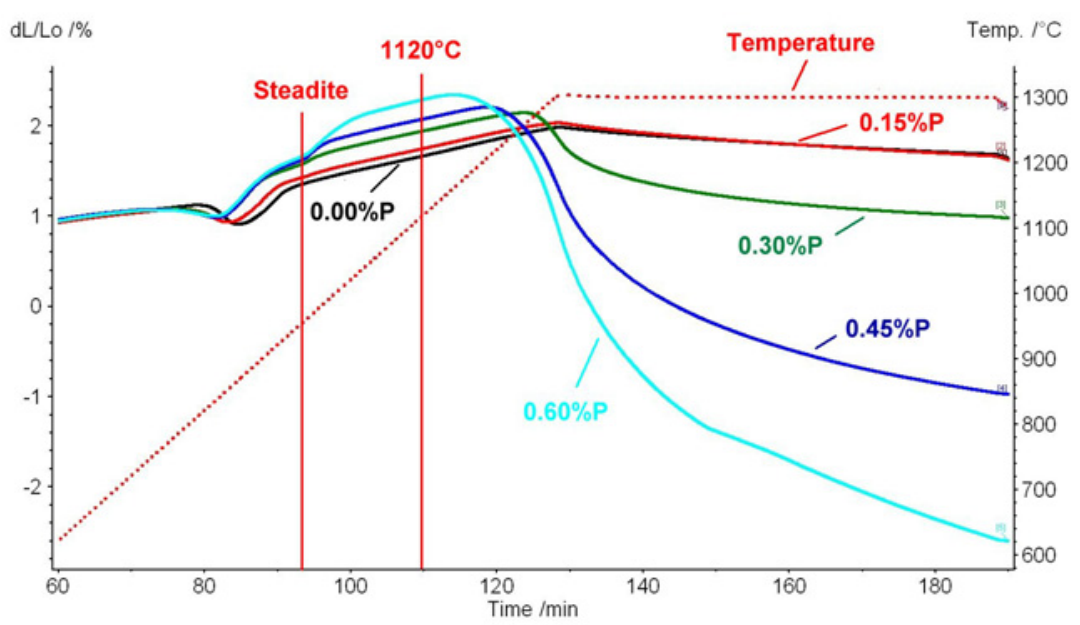

Fig.5. Dilatometric graphs of $\mathrm{Fe}-0.7 \% \mathrm{C}-\mathrm{x} \% \mathrm{P}$. Heating/cooling rate $+10 \mathrm{~K}$.min- $1.60 \mathrm{~min}$ $1300^{\circ} \mathrm{C}$ isothermal. $\mathrm{H}_{2}$ 5.0.

After this "jump", the subsequent expansion is almost identical for all P levels; with increasing $\mathrm{P}$ content the onset of shrinkage is however shifted to lower temperature, and also the isothermal shrinkage is enhanced, i.e. at these P levels activation has a pronounced effect on the dimensional behaviour. This higher shrinkage with increasing $\mathrm{P}$ content at first glimpse seems to disagree with the dimensional data given in Table 1 and Fig.2b which indicate higher expansion; however this can be attributed to the effect of the isothermal sintering temperature, which was $1300^{\circ} \mathrm{C}$ in the dilatometer compared to $1120^{\circ} \mathrm{C}$ in the pusher furnace. If checking in Fig.5 the dimensional behaviour at $\mathrm{T}=$ $1120^{\circ} \mathrm{C}$ (indicated in Fig. 5 by a vertical line), it is evident that here more $\mathrm{P}$ results in higher expansion, and it is only at higher temperatures that $\mathrm{P}$ enhances shrinkage during sintering. This behaviour has also been shown e.g. with sintering of $\mathrm{Al}$ alloys, i.e. that even pronounced expansion caused by transient liquid phase can be compensated for by subsequent persistent liquid phase which however requires sufficiently high sintering temperatures [36].

Furthermore, also the effect of the heating rate on dimensional behavior must be considered: with faster heating - as in the case of the specimens described in Table 1 - , more pronounced expansion through transient liquid phase can be expected. High heating rates as in the Degussa furnace are not possible in the dilatometer, with regard to the thermal shock sensitivity of the $\mathrm{Al}_{2} \mathrm{O}_{3}$ measuring system, but the effect of the heating rate on expansion by transient liquid phase is well known from other systems (see. e.g. [37]). In any case this underlines once more the importance of both the isothermal sintering temperature and of the heating rate up to sintering temperature for $\mathrm{P}$ alloyed steels.

The degassing and reduction behavior was studied by recording the masses $\mathrm{m} 18$ $\left(\mathrm{H}_{2} \mathrm{O}\right)$ and $\mathrm{m} 28\left(\mathrm{CO} / \mathrm{N}_{2}\right)$. From previous studies (e.g. [38] it is known that even when sintering in $\mathrm{H} 2$ atmosphere, only part of the oxygen is removed by $\mathrm{H} 2$, in the early stages of heating, while the major part is removed by carbothermal reduction at $\mathrm{T}>800^{\circ} \mathrm{C}$. This was found to hold also here, as shown for various compositions in Figs.6a-d and in comparison in Figs. $7 \mathrm{a}$ and $\mathrm{b}$ : the reduction peaks of $\mathrm{m} 18$ show an onset at about $200^{\circ} \mathrm{C}$, a maximum at about $330^{\circ} \mathrm{C}$, which is hardly shifted with varying $\mathrm{P}$ content (see Fig.7a) and a secondary 
$\mathrm{m} 18$ peak at about $500^{\circ} \mathrm{C}$ which increases with higher $\mathrm{P}$ content and is shifted to slightly higher temperatures.

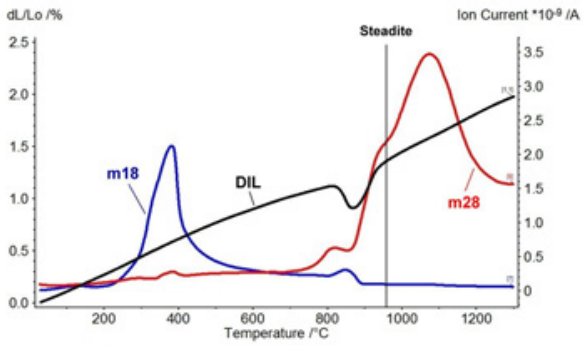

a) $\mathrm{Fe}-0.7 \% \mathrm{C}$

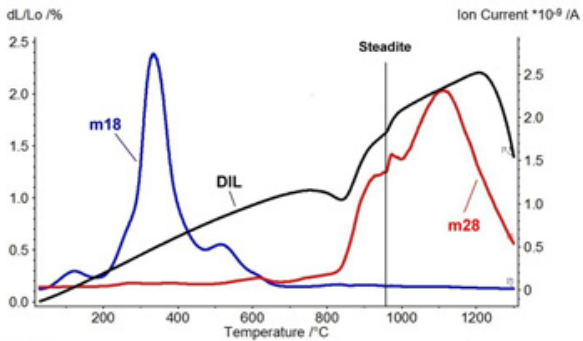

c) $\mathrm{Fe}-0.7 \% \mathrm{C}-0.45 \% \mathrm{P}$

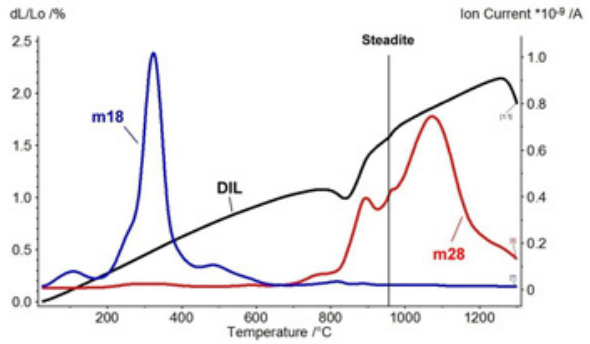

b) $\mathrm{Fe}-0.7 \% \mathrm{C}-0.30 \% \mathrm{P}$

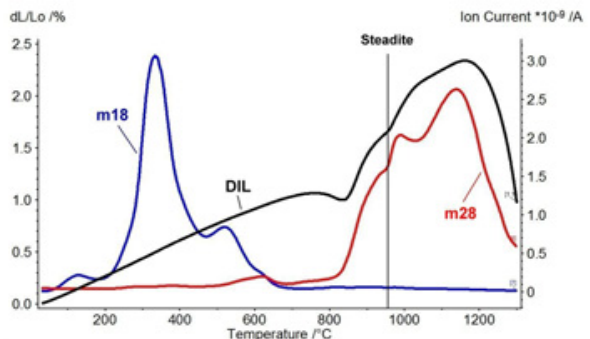

d) $\mathrm{Fe}-0.7 \% \mathrm{C}-0.60 \% \mathrm{P}$

Fig.6. Dilatometric graphs and mass spectra $\mathrm{m} 18$ and $\mathrm{m} 28$ for $\mathrm{Fe}-0.7 \% \mathrm{C}-\mathrm{x} \% \mathrm{P}$. Heating/cooling rate $+10 \mathrm{~K} . \mathrm{min}-1.60 \mathrm{~min} 1300^{\circ} \mathrm{C}$ isothermal. $\mathrm{H}_{2} 5.0$

At higher temperatures there is a pronounced peak - in fact at least a double peak - of $\mathrm{m} 28$ between about 850 and $1200^{\circ} \mathrm{C}$; the maximum of this peak is shifted from below 1100 to $1200^{\circ} \mathrm{C}$ if the $\mathrm{P}$ content is increased from 0.15 to $0.60 \%$. Here it should be considered that the thermodynamic stability of $\mathrm{P}_{2} \mathrm{O}_{3}$ is considerably higher than that of iron oxides (in contrast to that of $\mathrm{P}_{2} \mathrm{O}_{5}$ which is virtually identical to $\mathrm{Fe}_{3} \mathrm{O}_{4}$ ) [39]. In general, however, the reduction behavior of $\mathrm{Fe}-\mathrm{C}$ does not change significantly by addition of phosphorus, as visible from Fig. $7 \mathrm{~b}$ in which the $\mathrm{m} 28$ peaks virtually overlap, which is not too surprising when considering that dissolution of $\mathrm{P}$ in the matrix lowers its chemical activity and thus enhances reduction of the $\mathrm{P}$ oxides. This has also been shown very early by Naeser and Burmeister [23] who proved that sintering of compacts from phosphatized iron powders under standard conditions resulted in fully reduced specimens. On the other hand this shifting of the reduction peak might also be a consequence of the earlier densification in the latter material, i.e. a kinetic rather than a thermodynamic effect.

The most evident effect of $\mathrm{P}$ addition is however a small degassing peak at about $950^{\circ} \mathrm{C}$ which clearly coincides with the expansion observed in the dilatograms (see indicated temperature in Figs.6a-d and Fig. $7 \mathrm{~b}$ ). It is evident already at $0.3 \% \mathrm{P}$ and becomes more pronounced with higher $\mathrm{P}$ content. This can be regarded as a further indicator for formation of transient liquid phase at this temperature since it has been shown previously that liquid phase formation can enhance reduction processes [40]. The fact that this degassing and expansion effects occur at about the same temperature regardless of the $\mathrm{P}$ content indicates that it is actually a eutectic temperature, i.e. the ternary steadite eutectic at $955^{\circ} \mathrm{C}[18]$. 


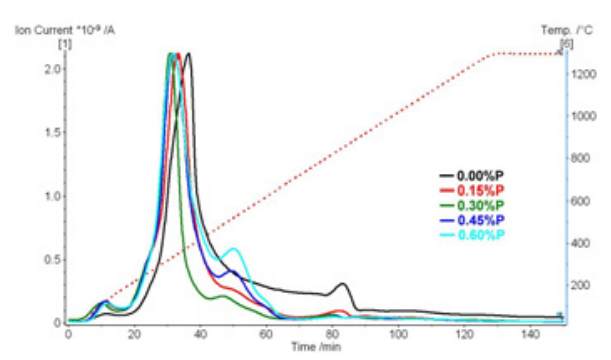

a) mass spectrometry graphs for $\mathrm{m} 18$

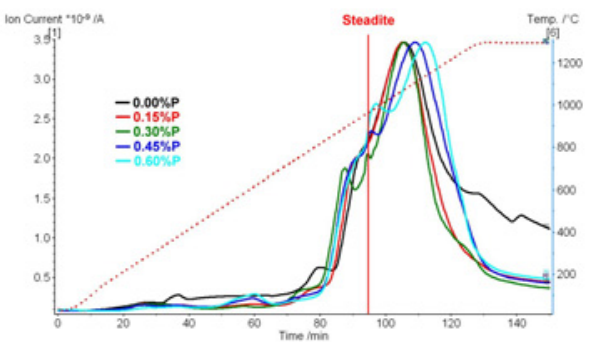

b) Mass spectrometry graphs for $\mathrm{m} 28$

Fig.7. Mass spectrometry graphs taken during dilatometric runs of $\mathrm{Fe}-0.7 \% \mathrm{C}-\mathrm{x} \% \mathrm{P}$. Heating/cooling rate $+10 \mathrm{~K}$.min- $1.60 \mathrm{~min} 1300^{\circ} \mathrm{C}$ isothermal. $\mathrm{H}_{2} 5.0$

\section{Conclusions}

The investigations carried out with $\mathrm{Fe}-\mathrm{C}-\mathrm{x} \% \mathrm{P}$ sintered in $\mathrm{H}_{2}$ have shown that for preparing sintered carbon steels with activation by phosphorus, the most effective way to introduce $\mathrm{P}$ is in fact admixing fine $\mathrm{Fe} 3 \mathrm{P}$ powder which yields the most regular microstructure and therefore also the best mechanical properties while both red $\mathrm{P}$ and $\mathrm{Fe} 2 \mathrm{P}$ resulted in formation of large pores, apparently due to agglomeration effects. Surprisingly there were some differences between the variants with admixed Fe3P and the "industrial variant" PASC 100.45 (in part diluted with Fe), the latter showing higher hardness but lower impact energy. The optimum $\mathrm{P}$ content with regard to the mechanical properties was in the range $0.30-0.45$ mass $\%$; at higher $\mathrm{P}$ contents the impact energy dropped considerably, which effect is well known from the literature.

Thermoanalytical studies with $\mathrm{Fe}-\mathrm{C}-\mathrm{x} \% \mathrm{P}$ ( $\mathrm{P}$ being added as $\mathrm{Fe} 3 \mathrm{P}$ ) performed in a dilatometer with mass spectrometry showed that compared to the furnace sintering described above, in the dilatometer $\mathrm{P}$ resulted in shrinkage rather than in expansion. This can be attributed to the different isothermal sintering temperature, which was much higher in the dilatometer $-1300^{\circ} \mathrm{C}$ compared to $1120^{\circ} \mathrm{C}-$, but also to the heating rate: the dilatograms revealed an expansion at about $950^{\circ} \mathrm{C}$ which is typical for transient liquid phase, and it is well known that the expansion caused by transient liquid phase is strongly affected by the heating rate. On the other hand, expansion caused by transient liquid phase can be compensated for by subsequent persistent liquid phase, which however requires accordingly higher temperatures.

The reduction behaviour of the Fe-P-x\%P compacts was hardly affected by the $\mathrm{P}$ addition, reduction being afforded at low temperatures $-200-500^{\circ} \mathrm{C}-$ by $\mathrm{H}_{2}$, and at higher temperatures, $800-1200^{\circ} \mathrm{C}$, by carbon; the most pronounced effect caused by $\mathrm{P}$ was a small but sharp degassing peak coinciding with the expansion at $950^{\circ} \mathrm{C}$, which once more confirms that activation by liquid phase has taken place here. This peak increased with higher $\mathrm{P}$ content but remained at the same temperature which corroborates that it is caused by a eutectic reaction.

\section{Acknowledgement}

The authors want to thank MIBA Sinter Austria GmbH, Vorchdorf, for supplying the starting powders used

\section{References}

[1] Lenel, FV.: U.S.Pat. 2.226,520 (1940) 
[2] Kieffer, R., Hotop, W.: Sintereisen und Sinterstahl. Vienna : Springer, 1948

[3] Eisenkolb, F.: Arch. Eisenhüttenwesen, vol. 24, 1953, p. 257

[4] Eisenkolb, F.: Planseeber. Pulvermet., vol. 2, 1954, p. 2

[5] Jones, WD.: Fundamental Principles of Powder Metallurgy. London : Edward Arnold, 1960

[6] Lenel, FV.: Powder Metallurgy - Principles and Applications. Princeton : MPIF, 1980

[7] Petzow, G., Exner, HE.: Powder Metall. Int., vol. 21, 1989, no. 2, p. 9

[8] Šalak, A.: Ferrous Powder Metallurgy. Cambridge : Cambridge Int. Sci. Publ., 1995

[9] Lindskog, P., Carlsson, A.: Powder Metall. Int., vol. 4, 1972, p. 39

[10] Lindskog, P.: Powder Metall., vol. 16, 1973, p. 374

[11] Molinari, A., Fontanari, V., Straffelini, G., Canteri, R.: Powder Metall., vol. 35, 1992, no. 4 , p. 285

[12] Straffelini, G., Fontanari, V., Molinari, A., Tesi, B.: Powder Metall., vol. 36, 1993, no. 2, p. 135

[13] Molinari, A., Straffelini, G., Canteri, R.: Int. J. Powder Metall., vol. 30, 1994, no. 3, p. 283

[14] Höganäs Handbook for Sintered Components. Vol.1: Material and Powder Properties. Höganäs : Höganäs AB, 2004

[15] Lindner, KH. In: Pulvermetallurgie in Wissenschaft und Praxis. Vol.11. Ed. H.Kolaska. Oberursel : DGM, 1995, p. 159

[16] Engdahl, P.: Modern Dev. in Powder Metall., vol. 20, 1988, p. 655

[17] Okamoto, H.: Phase diagrams of binary iron alloys. Materials Park OH : ASM, 1993

[18] Raghavan, VG.: Phase Diagrams of Iron Ternary Alloys. Part 3: Ternary Systems Containing Iron and Phosphorus. Calcutta : Indian Inst. of Metals, 1988, p. 33

[19] Miura, H., Tokunaga, Y.: Int. J.Powder Metall. \& Powder Technol., vol. 21, 1985, no. 4, p. 269

[20] Cias, A., Frydrych, J., Pieczonka, T.: Powder Metall. Int., vol. 21, 1989, no. 3, p. 13

[21] Khraisat, W., Nyborg, L.: Powder Metall., vol. 46, 2003, no. 3, p. 265

[22] Khraisat, W., Nyborg, L.: Mat. Sci. Technol., vol. 20, 2004, p. 705

[23] Naeser, G., Burmeister, H.: Arch. Eisenhüttenwesen, vol. 24, 1953, p. 251

[24] Jangg, G., Drozda, M., Danninger, H., Eder, G.: Powder Metall. Int., vol. 16, 1984, no. 6 , p. 264

[25] Lindskog, P., Tengzelius, J., Kvist, SA.: Modern Dev. in Powder Metall., vol. 10, 1977, p. 97

[26] Tengzelius, J.: Metal Powder Rep., vol. 48, 1993, no. 1, p. 36

[27] Lund, J.: Modern Dev. in Powder Metall., vol. 16, 1985, p. 3

[28] Üregen, B., Danninger, H. In: Advances in Structural PM Component Production. Proc. EuroPM97 Munich. Shrewsbury : EPMA, 1997, p. 319

[29] Danninger, H.: Powder Metall. Int., vol. 24, 1992, no. 2, p. 73

[30] Danninger, H., Jangg, G., Weiss, B., Stickler, R.: Powder Metall. Int., vol. 25, 1993, no. 4 , p. 170 ; no. 5 , p. 219

[31] Danninger, H. In: Proc. 8th Int. PM Conf. CSFR. Vol. 1. Piestany, 1992, p. 81

[32] Danninger, H., Pöttschacher, R., Bradac, S., Šalak, A., Seyrkammer, J.: Powder Metall., vol. 48, 2005, no. 1, p. 23

[33] Handbook of Chemistry and Physics. 67th ed. Boca Raton FL : CRC Press

[34] Šalak, A.: Powder Metall. Int., vol. 18, 1986, no. 4, p. 266

[35] McMordie, BG.: Progr. Powder Metall., vol. 38, 1982, p. 301

[36] Danninger, H., Neubing, HC., Gradl, J. In: Proc. PM'98 Granada. Vol. 5. Shrewsbury : EPMA, 1998, p. 272 
[37] Danninger, H.: Powder Metall. Int., vol. 24, 1992, no. 3, p. 73

[38] Danninger, H., Gierl, C.: Sci. Sintering, vol. 40, 2008, no. 1, p. 33

[39] Glassner, AR.: The Thermochemical Properties of the Oxides, Chlorides, and Fluorides to $2500^{\circ}$ K. Washington D.C. : U.S. Atomic Energy Comm. Rep. ANL-5750, 1957

[40] Oro, R., Campos, M., Gierl-Mayer, C., Danninger, H., Torralba, JM.: Met. Mat. Trans. A, vol. 46, 2015, p. 1349 